\section{El compromiso social de la universidad latinoamericana del siglo XXI. Entre el debate y la acción}

\author{
Néstor Horacio Cecchi, Juan José Lakonich; \\ Dora Alicia Pérez y Andrés Rotstein (2009). \\ Buenos Aires, Argentina: IEC-CONADU. \\ 193 páginas. Disponible en versión digital.
}

Reseñado por María Soledad Alvez

Universidad Nacional de Mar del Plata, Argentina.

licmsoledadalves@gmail.com

En esta publicación los autores realizan un recorrido conceptual sobre la relación de la universidad con la sociedad, así como un análisis de experiencias en territorio que se llevan a cabo desde diferentes instituciones de educación superior. Las mismas constituyen un aporte para pensar el compromiso social de las universidades de América Latina y el Caribe, en especial en estos tiempos y este contexto.

Explicitan que las ideas de compromiso social de las universidades estuvieron presentes en diferentes momentos, particularmente, desde la Reforma de 1918, aunque en Argentina y la región una serie de acontecimientos sociales y políticos obstaculizó el diálogo genuino entre las universidades y el resto de la comunidad. Los autores plantean que la responsabilidad ética de la universidad es contribuir a reducir la distancia entre los grupos hegemónicos de poder y las situaciones de exclusión social de los grupos más desfavorecidos, identificar los problemas y demandas reales, coordinar dentro de la comunidad las acciones correspondientes, reorientar y recrear, en forma articulada, las actividades de docencia, investigación y extensión. En la formación de los estudiantes deberían contemplarse, entre otras, las dimensiones éticas, comunitarias, epistemológicas y metodológicas.

Por ello, la universidad debe repensar sus prácticas pedagógicas, explorar los procesos de enseñanza y de aprendizaje a la luz de la pertinencia social de sus acciones. Se valoran aquellas prácticas enmarcadas en las concepciones de cognición situada o contextualizada, en tanto la condición situacional posibilita la resignificación de los aprendizajes.

Los autores entienden que el conocimiento resulta un insumo clave en la transformación social; por ello, consideran que es imperativo pensar en términos de gestión social del conocimiento, tal como lo plantea Pérez Lindo. Su producción, su apropiación y su uso, deben avanzar éticamente hacia modelos transdisciplinares por sobre los sistemas en los que aún están fuertemente enraizados los modelos disciplinares. Es urgente analizar los currículos vigentes y propiciar las modificaciones necesarias. Muchas universidades han comenzado a responderse algunos de los interrogantes planteados a partir del diálogo entre sus diferentes actores, con otras universidades, con autoridades gubernamentales, con organizaciones sociales y con el resto de
A 100 años de la Reforma Universitaria de 1918 / Reseña de libros

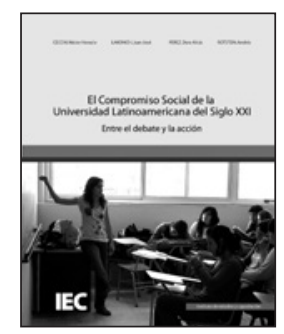

la sociedad de la que forman parte. Se debe revisar, esclarecer y transformar la "desenseñanza" de valores de equidad, justicia y verdad. Se trata, en suma, de la construcción de un nuevo ethos dentro de la universidad.

El compromiso social es un concepto polisémico y en permanente reconstrucción. En términos generales, refiere a una política de calidad ética del desempeño de la comunidad universitaria (estudiantes, docentes y personal administrativo) a través de la gestión responsable de los impactos educativos, cognitivos, laborales y ambientales que la universidad genera, en un diálogo participativo con la sociedad para mejorar la academia y promover el desarrollo humano sostenible, superar las iniciales concepciones asistencialistas y fortalecer la asociatividad, la confianza y la conciencia cívica, es decir "el capital social". Finalmente, en esta publicación que surge por iniciativa de la Agremiación Docente Universitaria Marplatense (ADUM) y su Centro de Estudios Sociales y Sindicales (CeSyS), luego editada por IEC-CONADU, los autores entienden que una genuina articulación solo se logrará con la participación activa y comprometida de todos los actores sociales, universitarios y no universitarios, transformando los escenarios de interacción en verdaderas comunidades de aprendizaje. 